in vivo $35: 283-289(2021)$

doi:10.21873/invivo.12257

\title{
Effects of Different Media on Human T Regulatory Cells Phenotype
}

\author{
MAGDALENA GŁACZYNSKA, MAJA MACHCINSKA and KATARZYNA DONSKOW-LYSONIEWSKA
}

Laboratory of Parasitology, General Karol Kaczkowski

Military Institute of Hygiene and Epidemiology, Warsaw, Poland

\begin{abstract}
Background/Aim: Functional and quantitative Treg cell defects have been identified in a variety of autoimmune diseases. Therefore, Tregs are a major pharmaceutical target for these disorders. In the last decades, studies have been mainly focused on the identification and experimental understanding of the activity of Tregs and their mechanisms of action. Materials and methods: This study describes how overnight storage of isolated peripheral blood mononuclear cells in different media (PBS pH 7.3, PBS pH 7.3 containing $0.5 \%$ BSA, RPMI 1640 and RPMI 1640 containing 10\% FBS) affects the viability and expression of the commonly used markers for Tregs identification: CD25, CD127, CTLA-4, GITR, PD-1, FoxP3 and Helios. Results: Incorrectly selected storage conditions (temperature, time, medium) may affect the expression of surface and intracellular markers, thus, compromising the quality of the obtained results. Conclusion: Appropriate protocols of cell isolation and storage are important for providing appropriate conditions for cell growth. This is crucial when analyzing small cell populations like Tregs.
\end{abstract}

Modern disease diagnostics, as well as scientific research, largely use blood-based testing. Peripheral blood mononuclear cells (PBMCs) are a blood fraction consisting of $\mathrm{T}$ lymphocytes, B lymphocytes, natural killer cells, monocytes, and dendritic cells. Therefore, PBMCs are a good cell population to study the mechanisms of the immune system, immunodeficiencies, and autoimmune diseases (1-3).

One of the most important subpopulations of $\mathrm{T}$ cells are $\mathrm{T}$

This article is freely accessible online.

Correspondence to: Maja Machcińska, Laboratory of Parasitology, General Karol Kaczkowski Military Institute of Hygiene and Epidemiology, Kozielska 4, 01-163 Warsaw, Poland. Tel: +48 261853126, e-mail: maja.machcinska@wihe.pl

Key Words: Peripheral blood mononuclear cells (PBMC), PBMC storage, cell viability, Tregs, T cells. regulatory cells (Tregs). They are characterized by the ability to suppress the immune response, which is of great importance in maintaining homeostasis and in autoimmune phenomena (4-10). Tregs are involved in inhibiting the suppressive activity of $\mathrm{T}$ cells and the prevention of autoimmune diseases (9). Impairment of Tregs function and development may be one of the causes of autoimmune diseases and other dysfunctions $(6,10)$. Now, a lot of attention has been focused not only on $\mathrm{CD}^{+}$, but also on $\mathrm{CD}^{+}$Tregs $(11,12)$.

Unfortunately, it is not always possible to perform planned experiments immediately after cell isolation, e.g. due to the time of blood collection from the donor or patient, experimental procedure or availability of reagents. Knowledge of the influence of storage conditions on cells is essential, especially when studying rare cells like Tregs. The first parameter, that seems to be the most important for cell storage is viability, which can affect the yield and function of cells, and consequently the results. Therefore, it is important to maintain a high viability of cells, especially when cells are designed for further experimental procedures. However, cell storage can affect not only cell viability but also the expression of surface and intracellular markers specific for $\mathrm{T}$ cell identification and function, especially Tregs.

For these reasons, we investigated how storage of isolated PBMCs overnight at $4^{\circ} \mathrm{C}$ in different media (PBS pH 7.3, PBS pH 7.3 containing 0.5\% BSA, RPMI 1640, and RPMI 1640 containing $10 \%$ FBS) affects their viability, expression of $\mathrm{T}$ cell markers and the frequencies of $\mathrm{CD}^{+}$and $\mathrm{CD}^{+}$ Tregs.

\section{Materials and Methods}

PBMC isolation. Human PBMCs were isolated from buffy coats obtained from whole blood ( $\mathrm{n}=10,8$ male and 2 female) at the Regional Blood Donation and Blood Treatment Center in Warsaw, Poland. Blood was collected into sodium citrate bag (CompoFlow, Fresenius Kabi, Bad Homburg, Germany). Samples were stored, prepared and maintained at room temperature (RT). Blood was diluted 1:1 with PBS pH 7.3 (Biowest SAS, Nuaillé, France), layered 


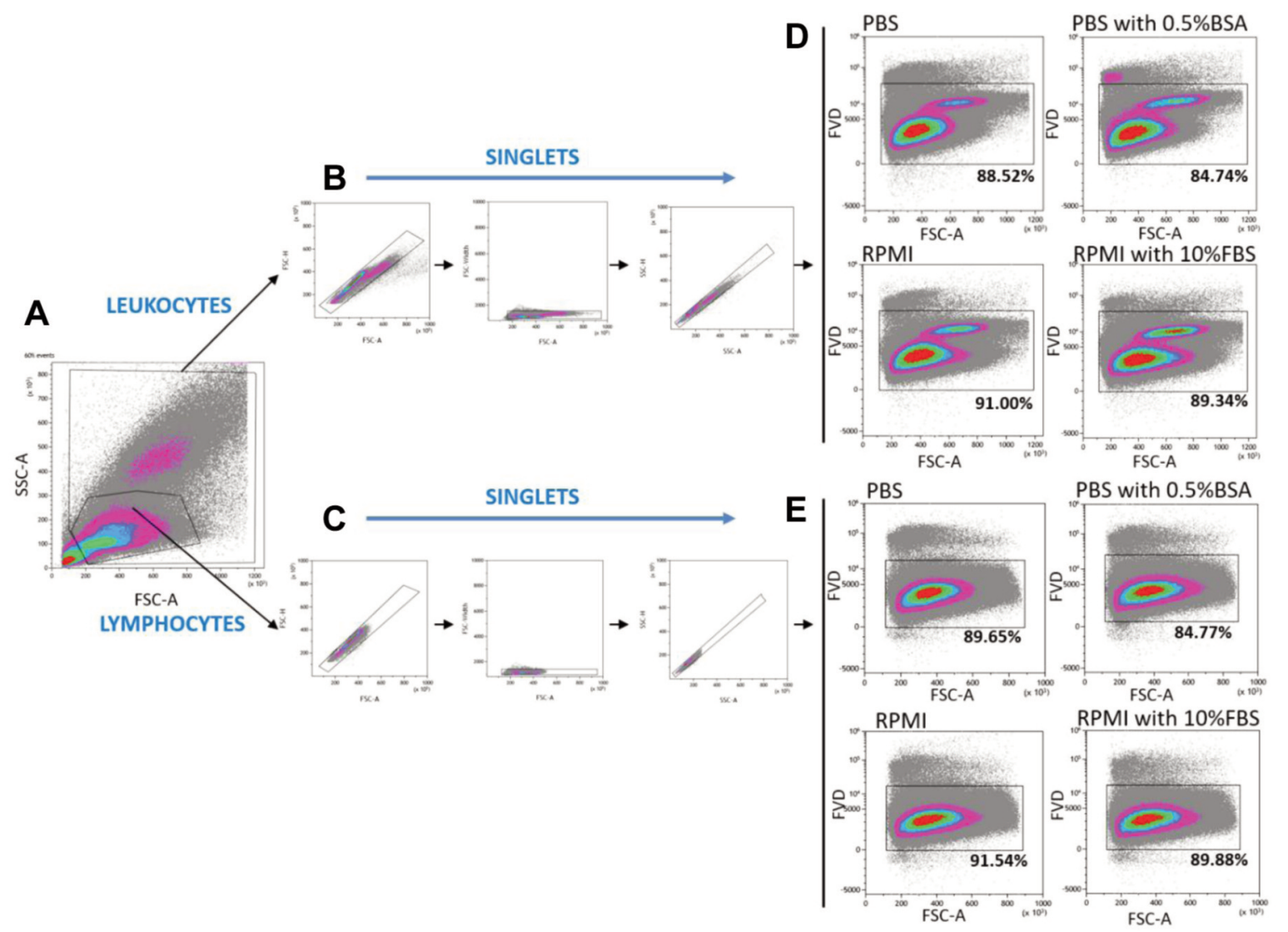

Figure 1. Viability of PBMC incubated overnight at $4^{\circ} \mathrm{C}$ in PBS, PBS containing $0.5 \%$ BSA, RPMI 1640 and RPMI 1640 containing $10 \%$ FBS, determined by flow cytometry. Gating strategy for flow cytometric analysis of the leukocyte (granulocytes and lymphocytes) and lymphocyte population to identify liveldead cells. A time gate was initially applied to exclude any electronic noise and artifact (not shown here). Next, based on size and granularity, lymphocytes and leukocytes were gated in a forward scatter area (FSC-A) versus side scatter area (SSC-A) plot (A). Then, separately for leukocyte (B) and lymphocyte (C) populations, doublet cells were excluded using FSC-A/FSC-height (FSC-H), FSC-A/FSCWidth and SSC-A/SSC-height (FSC-H) parameters. Within the singlet cell population, viable leukocytes $(D)$ and lymphocytes $(E)$ were gated based on the dim expression of the Fixable Viability Dye (FVD). Results are average percentages of viable cells for all donors ( $n=10)$. Representative plots are presented.

on Lymphosep (Biowest SAS, Nuaillé, France), and centrifuged at $400 \times g$ for 20 min at RT (no brake). Then, PBMCs were washed twice with PBS pH 7.3 by centrifugation at $453 \times g$ for $10 \mathrm{~min}$ at RT. Contaminating red blood cells were lysed by adding $10 \mathrm{ml}$ Red Blood Cell Lysis Buffer (BioVision, Milpitas, CA, USA) to less than $1 \times 10^{8}$ PBMCs. After a 10 -min incubation at RT, the cells were washed with PBS pH 7.3 by centrifugation at $400 \times g$ for 5 min at RT. The total PBMC number, and viability were counted using the Muse Count and Viability Kit (Merck-Millipore, Billerica, MA, USA) followed by a Muse Cell Analyzer (Merck-Millipore, Billerica, MA, USA) in accordance with the manufacturer's instructions. The viability of isolated PBMCs was $>97.2 \%$.

PBMC storage. A total of $5 \times 10^{6}$ freshly isolated PBMCs were suspended in $5 \mathrm{ml}$ of one of the following media: PBS pH 7.3, PBS $\mathrm{pH} 7.3$ supplemented containing $0.5 \%$ bovine serum albumin (PBS pH 7.3 containing $0.5 \%$ BSA) (VWR International, Darmstadt, Germany), RPMI 1640 (Biowest SAS, Nuaillé, France) and RPMI 1640 supplemented containing $10 \%$ fetal bovine serum (RPMI
1640 containing 10\% FBS) (Biowest SAS, Nuaillé, France) and stored overnight $(24 \mathrm{~h})$ at $4{ }^{\circ} \mathrm{C}$. After incubation, PBMCs from each medium were washed in PBS $\mathrm{pH} 7.3$ by centrifugation at $453 \times g$ for $5 \mathrm{~min}$ at RT. Viability was determined by Muse Cell Analyzer and flow cytometry. To allow direct count and viability determinations, $20 \mu 1$ PBMCs were mixed with $380 \mu 1$ The Muse Count and Viability Reagent. After 5 min of incubation, stained cells were analyzed in the Muse Cell Analyzer.

Flow cytometry analysis. For analysis of T cell viability by flow cytometry (FACS), PBMCs were washed again with PBS pH 7.3 and stained with Fixable Viability Dye eFluor 455UV (eBioscience, San Diego, CA, USA), according to manufacturer's instruction, to identify live and dead cells. Additionally, $\mathrm{T}$ cell immunophenotyping was performed using the fluorochromeconjugated monoclonal antibodies: CD3-eFluor506 (clone UCHT1; eBioscience), CD4-BUV496 (clone SK3; BD Biosciences, San Diego, CA, USA), CD8-APC-eFluor780 (clone RPA-T8; eBioscience), CD127-eFluor450 (clone eBioRDR5; eBioscience), 
A) PBS

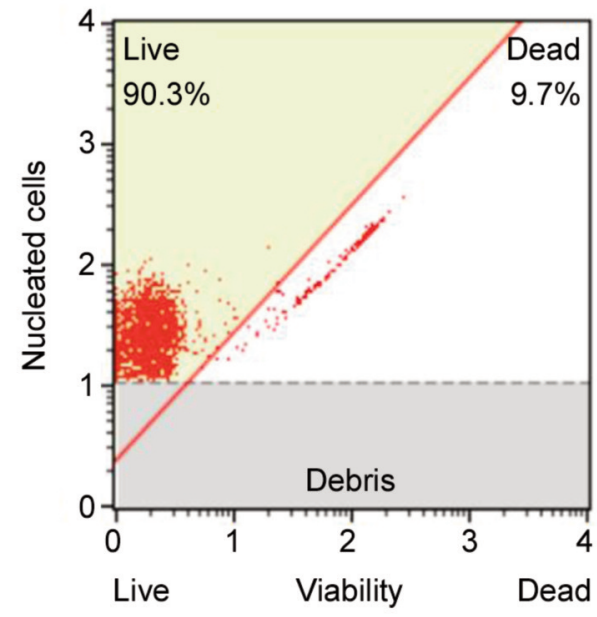

C) RPMI

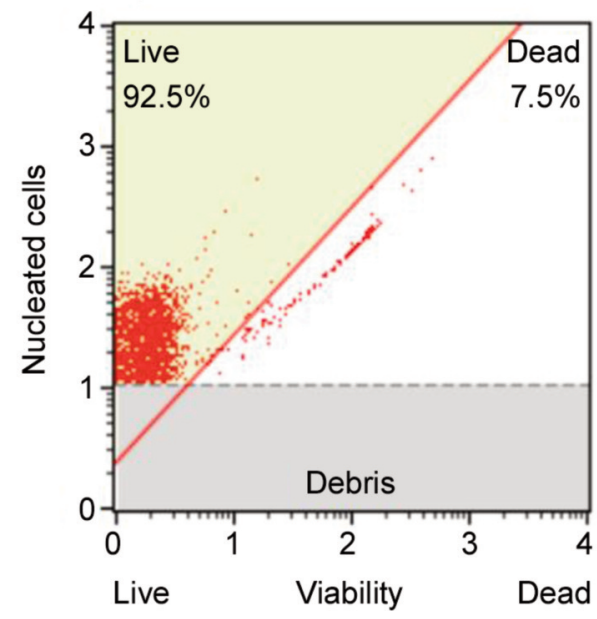

B) PBS with $0.5 \% \mathrm{BSA}$

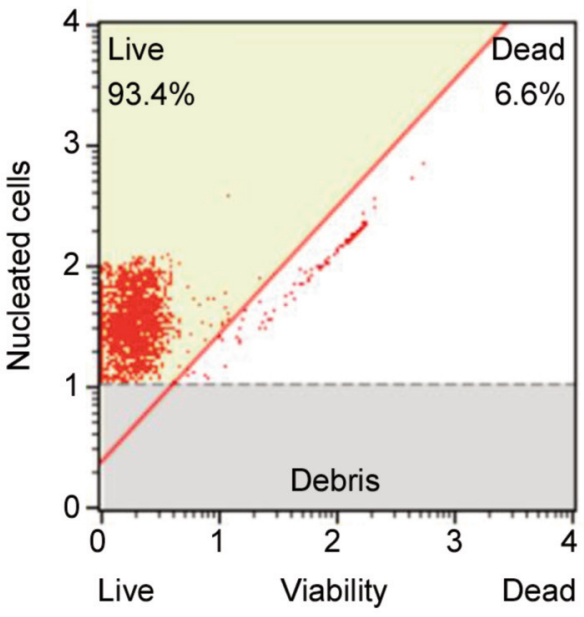

D) RPMI with $10 \% \mathrm{FBS}$

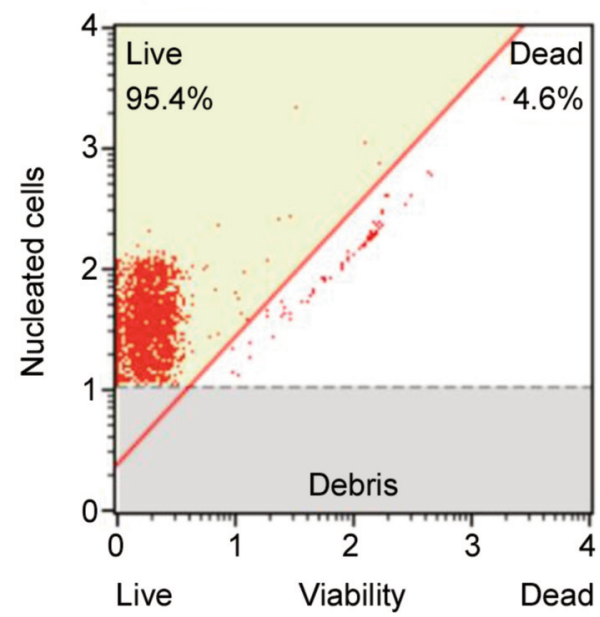

Figure 2. Viability of PBMCs incubated overnight at $4^{\circ} \mathrm{C}$ in PBS, PBS containing $0.5 \%$ BSA, RPMI 1640 and RPMI 1640 containing $10 \%$ FBS, as determined by the Muse Cell Analyzer. The representative plots show the average percentage of live and dead PBMCs stored overnight at $4^{\circ} \mathrm{C}$ in various media: A) PBS; B) PBS containing 0.5\% BSA; C) RPMI 1640; D) RPMI 1640 containing $10 \%$ FBS.

CTLA-4-PE (clone 14D3; eBioscience), GITR-BV610 (clone 621; BioLegend, San Diego, CA, USA) and PD-1-FITC (clone MIH4; eBioscience). Cells were incubated for $30 \mathrm{~min}$ at $4^{\circ} \mathrm{C}$, then washed twice with Cell Wash (Becton Dickinson, San Jose, CA, USA) containing $0.5 \%$ BSA and fixed and permeabilized using FoxP3/Transcription Factor Staining Buffer Set (eBioscience, San Diego, CA, USA) according to the manufacturer's instructions. For intracellular staining, monoclonal antibodies against FoxP3-APC (clone PCH101) and Helios-PE-Cy7 (clone 22F6) (both from eBioscience) were used. After $30 \mathrm{~min}$ incubation, cells were washed and acquired using CytoFLEX LX (Beckman Coulter, Inc, Brea, CA, USA). Data were analyzed using Kaluza Analysis Software version 2.1 (Beckman Coulter). The CytoFLEX LX was calibrated daily by the Military Institute of Hygiene and Epidemiology Flow Cytometry Laboratory staff using CytoFLEX Daily QC
Fluorospheres (Beckman Coulter, Inc, Brea, CA, USA). Compensation settings were conducted using single-stained cells or VersaComp Antibody Capture Bead Kit (Beckman Coulter, Inc, Brea, CA, USA). Positive staining and gating strategy were determined by comparison to an unstained control and a fluorescence minus one (FMO) control. The lymphocytes were gated based on morphological parameters on a forward $v s$. side scatter (FSC-A/SSC-A) plot. Cell aggregates were removed from the analysis using a sequential gating strategy with forward scatter (FSC) and side scatter (SSC) parameters, as presented in Figure 1. Viable PBMCs were identified based on the dim expression of the Fixable Viability Dye. The results are shown as the percentage of positively labeled cells and the mean fluorescence intensity (MFI) was calculated by CytoFLEX LX. 
in vivo $35: 283-289(2021)$

Table I. Effect of overnight incubation at $4^{\circ} \mathrm{C}$ in different media on T lymphocyte markers.

\begin{tabular}{|c|c|c|c|c|c|c|c|c|c|c|}
\hline & \multicolumn{5}{|c|}{ CD4 T cell } & \multicolumn{5}{|c|}{ CD8 T cell } \\
\hline & \multirow{2}{*}{$\begin{array}{l}\text { Freshly } \\
\text { isolated }\end{array}$} & \multicolumn{4}{|c|}{$24 \mathrm{~h}$ incubation in } & \multirow{2}{*}{$\begin{array}{l}\text { Freshly } \\
\text { isolated }\end{array}$} & \multicolumn{4}{|c|}{$24 \mathrm{~h}$ incubation in } \\
\hline & & PBS & $\begin{array}{c}\text { PBS } \\
\text { with BSA }\end{array}$ & RPMI & $\begin{array}{c}\text { RPMI } \\
\text { with FBS }\end{array}$ & & PBS & $\begin{array}{c}\text { PBS } \\
\text { with BSA }\end{array}$ & RPMI & $\begin{array}{c}\text { RPMI } \\
\text { with FBS }\end{array}$ \\
\hline $\mathrm{CD} 25$ & $8.09 \pm 1.67$ & $5.46 \pm 1.28^{\mathrm{a}^{* *}}$ & $3.68 \pm 1.34^{\mathrm{a}^{* *} ; \mathrm{b}^{*}}$ & $3.93 \pm 1.13^{\mathrm{a}^{* *}}$ & $3.70 \pm 1.18^{\mathrm{a}^{* *} ; \mathrm{b}^{*}}$ & $0.31 \pm 0.12$ & $0.16 \pm 0.07^{\mathrm{a}^{* *}}$ & $0.10 \pm 0.06^{\mathrm{a}^{* *}}$ & $0.09 \pm 0.04^{\mathrm{a}^{* *}}$ & $0.09 \pm 0.03^{\mathrm{a}^{* *}}$ \\
\hline CTLA-4 & $0.40 \pm 0.40$ & $1.21 \pm 0.70$ & $2.23 \pm 0.94^{\mathrm{a}^{* *} ; \mathrm{b}^{*}}$ & $1.65 \pm 0.70^{\mathrm{a}^{*}}$ & $2.10 \pm 0.80^{\mathrm{a}^{* *}}$ & $0.40 \pm 0.40$ & $0.67 \pm 0.30$ & $1.52 \pm 1.04^{\mathrm{a}^{*}}$ & $1.01 \pm 0.65$ & $1.18 \pm 0.63^{\mathrm{a}^{*}}$ \\
\hline GITR & $0.37 \pm 0.16$ & $0.38 \pm 0.16$ & $0.43 \pm 0.14$ & $0.40 \pm 0.23$ & $0.49 \pm 0.19$ & $0.05 \pm 0.03$ & $0.06 \pm 0.04$ & $0.10 \pm 0.05$ & $0.07 \pm 0.04$ & $0.09 \pm 0.04$ \\
\hline PD-1 & $6.46 \pm 3.54$ & $13.11 \pm 4.72$ & $17.24 \pm 2.75^{\mathrm{a}^{*}}$ & $10.96 \pm 2.72^{\mathrm{c}^{*}}$ & $12.82 \pm 4.97$ & $11.50 \pm 5.56$ & $12.64 \pm 5.00$ & $16.08 \pm 6.81$ & $11.84 \pm 4.74$ & $13.25 \pm 5.87$ \\
\hline FoxP3 & $4.42 \pm 0.68$ & $3.82 \pm 0.57$ & $3.08 \pm 0.54^{\mathrm{a}^{*}}$ & $4.03 \pm 0.59$ & $4.15 \pm 0.64^{\mathrm{c}^{*}}$ & $0.37 \pm 0.21$ & $0.34 \pm 0.28$ & $0.87 \pm 0.50$ & $1.72 \pm 1.49^{\mathrm{b} *}$ & $1.63 \pm 0.94^{a^{*} ; b^{*}}$ \\
\hline Helios & $3.46 \pm 0.61$ & $3.76 \pm 0.57$ & $2.95 \pm 0.53^{\mathrm{b}^{*}}$ & $3.17 \pm 0.46$ & $3.17 \pm 0.48$ & $6.62 \pm 16.94$ & $6.40 \pm 17.03$ & $6.62 \pm 16.58$ & $6.42 \pm 16.28$ & $6.87 \pm 16.43$ \\
\hline
\end{tabular}

PBMCs were incubated overnight at $4^{\circ} \mathrm{C}$ in PBS, PBS containing 0.5\% BSA, RPMI 1640 and RPMI 1640 containing $10 \%$ FBS. The table presents the average percentages $( \pm \mathrm{SD})$ of $\mathrm{CD}^{+}$and $\mathrm{CD} 8^{+} \mathrm{T}$ cells positively expressing surface markers identified by using flow cytometry on freshly isolated $\mathrm{T}$ cells from all donors and after incubation $(\mathrm{n}=10) .{ }^{*} p<0.05,{ }^{*} p<0.0001$ (ANOVA or Kruskal-Wallis); ${ }^{\mathrm{a}}$ compared to freshly isolated; ${ }^{\mathrm{b}}$ compared to $24 \mathrm{~h}$ incubation in PBS; ${ }^{\mathrm{c}}$ compared to $24 \mathrm{~h}$ incubation in PBS containing $0.5 \% \mathrm{BSA}$; ${ }^{\mathrm{d}}$ compared to $24 \mathrm{~h}$ incubation in RPMI.

Statistics. Data are expressed as the mean \pm standard deviation (SD) and were analyzed by ANOVA or Kruskal-Wallis $\mathrm{H}$ test using GraphPad Prism 8 software (GraphPad Software, La Jolla, CA, USA). A $p$-value $<0.05$ was considered statistically significant.

\section{Results}

Effect of overnight incubation at $4^{\circ} \mathrm{C}$ on PBMC viability. First, we investigated the effects of overnight incubation at $4^{\circ} \mathrm{C}$ on PBMCs in four different media: PBS, PBS containing $0.5 \%$ BSA, RPMI 1640 and RPMI 1640 containing 10\% FBS. Cells were analyzed using Muse Cell Analyzer. As expected, PBMC viability after overnight incubation at $4^{\circ} \mathrm{C}$ was lower compared to freshly isolated PBMCs (97.08\%). We observed a statistically significant decrease in the viability of PBMCs stored in PBS, RPMI 1640 containing 10\% FBS and PBS containing 0.5\% BSA $(p<0.05)$. The highest PBMC viability after overnight incubation at $4{ }^{\circ} \mathrm{C}$ was observed for cells stored in RPMI 1640 containing $10 \%$ FBS $(96.6 \%)$ and PBS containing $0.5 \%$ BSA (94.2\%) (Figure 2D and B). The lowest viability was obtained for cells stored in RPMI 1640 alone (93.4\%) and PBS (91.8\%) (Figure 2A and C).

Effect of overnight incubation at $4^{\circ} \mathrm{C}$ on $\mathrm{T}$ lymphocyte markers. Before investigating the effects of overnight PBMC incubation at $4^{\circ} \mathrm{C}$ in PBS, PBS containing $0.5 \%$ BSA, RPMI 1640 or RPMI 1640 containing $10 \%$ FBS on T lymphocyte markers, we analyzed the viability of the lymphocyte population. The high viability of cells is very important to obtain reliable results when immunophenotyping using flow cytometry.

After $24 \mathrm{~h}$ incubation, the highest lymphocyte viability was observed in RPMI 1640 (91.54\%) and next in RPMI
1640 containing $10 \%$ FBS $(89.88 \%)$. A lower percentage of live lymphocytes was noted in PBS $(89.65 \%)$, and significantly lower in PBS containing 0.5\% BSA (84.77\% vs. $91.07 \%$ of freshly isolated lymphocytes) (Figure 1E).

Additionally, we analyzed the viability of the whole leukocyte population, which may be related to the results obtained from the Muse Cell Analyzer. Using FACS analysis based on morphological parameters, the leukocyte (granulocytes and lymphocytes) population was identified. Similarly, for leukocytes, the highest viability was observed for cells stored in RPMI 1640 (91.00\%) and next for RPMI 1640 containing 10\% FBS $(89.34 \%)$ and PBS (88.52\%). Statistically lower viability of leukocytes was observed in PBS containing 0.5\% BSA ( $84.74 \%$ vs. $91.31 \%$ of freshly isolated leukocytes) (Figure 1D).

Next, we investigated how the expression of markers specific for $\mathrm{T}$ cell identification and function, especially $\mathrm{T}$ regulatory cells, changes. Identification of $\mathrm{T}$ cell populations was based on the gating strategy presented on Figures 1 and 3. Live $\mathrm{T}$ cells were defined as $\mathrm{CD} 3{ }^{+} \mathrm{CD} 4^{+}$and $\mathrm{CD} 3^{+} \mathrm{CD} 8^{+}$ cells and then, the expression of single markers was analyzed by flow cytometry. Despite the fact that the percentage of $\mathrm{CD}^{+}$and $\mathrm{CD}^{+} \mathrm{T}$ cells did not change significantly after overnight storage at $4^{\circ} \mathrm{C}$ in various media (data not shown), the obtained results showed that some markers are more sensitive to overnight storage (Table I).

We observed an incubation-induced alteration in the expression of cluster of differentiation 25 (CD25), cytotoxic $\mathrm{T}$ cell antigen 4 (CTLA-4), programmed death receptor 1 (PD-1) and forkhead box P3 (FoxP3) on $\mathrm{CD}^{+}$and $\mathrm{CD} 8^{+} \mathrm{T}$ cells. A statistically significant lower percentage of $\mathrm{CD} 4^{+} \mathrm{CD} 25^{+}$and $\mathrm{CD} 8^{+} \mathrm{CD} 25^{+} \mathrm{T}$ cells was noted after overnight incubation in all four different media compared to freshly isolated cells. In contrast, the percentage of both $\mathrm{CD}^{+}$and $\mathrm{CD} 8^{+} \mathrm{T}$ cells with 

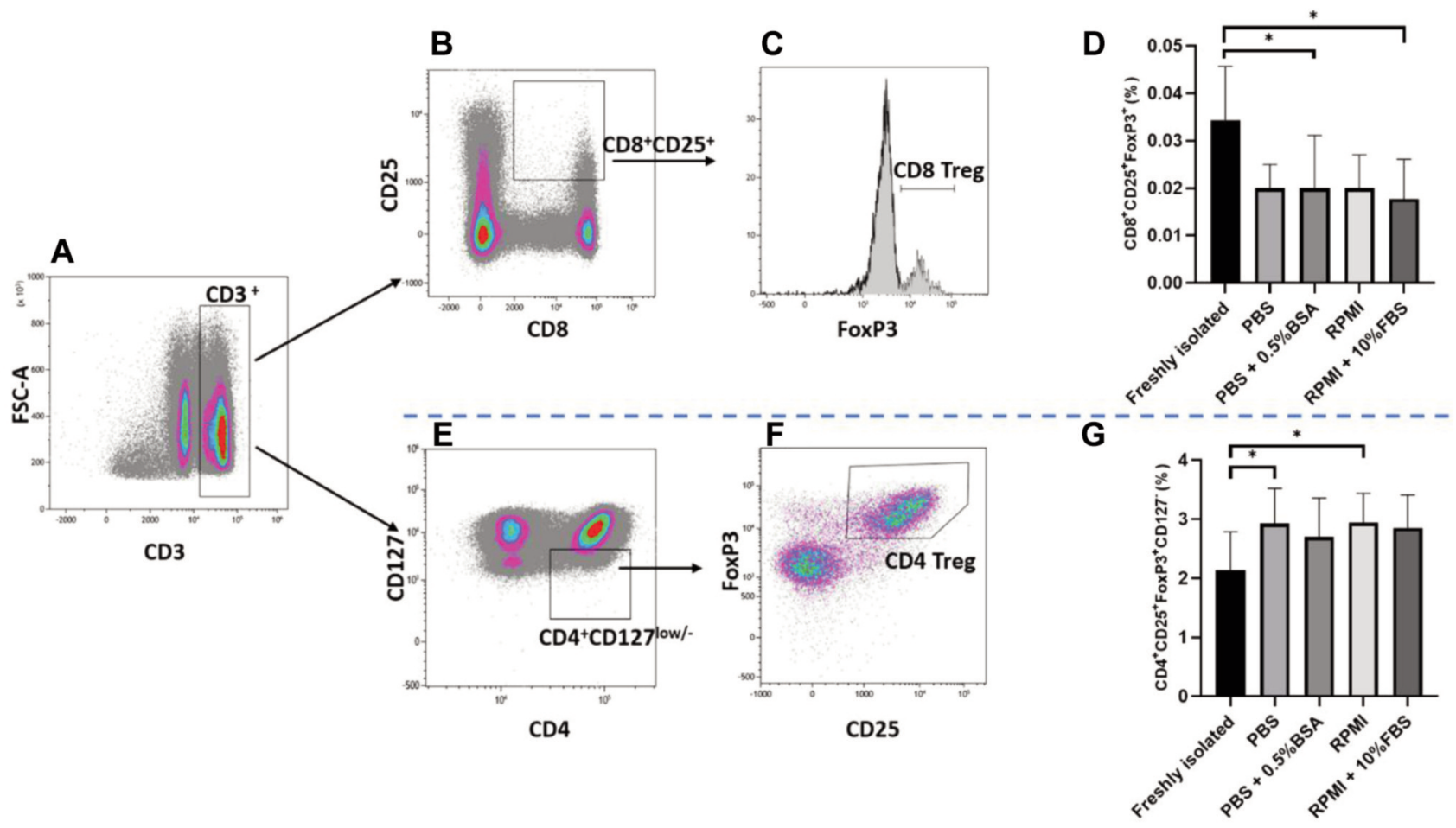

Figure 3. Effect of overnight incubation at $4^{\circ} \mathrm{C}$ in different media on $\mathrm{CD}^{+}$and $\mathrm{CD} 8^{+}$Tregs. Freshly isolated and overnight incubated at $4^{\circ} \mathrm{C}$ in different media (PBS, PBS containing 0.5\% BSA, RPMI 1640 and RPMI 1640 containing $10 \%$ FBS) $C D 4^{+}$and CD8 $8^{+}$Tregs were analyzed by FACS. The gating strategy of $\mathrm{CD}^{+}$and $\mathrm{CD} 8^{+}$Tregs is presented on dot plots from one representative donor. Lymphocytes were identified based on their forward-and side-scatter properties, and doublet cells and dead cells were eliminated through the use of a viability dye (show in Figure 1), followed by expression of CD3 (A). CD8 Tregs were next identified by CD8 and CD25 (B) and FoxP3 (C) expression. CD4 Tregs were identified as $C D 4^{+} C D 127$ low/- cells $(E)$ with CD25 and FoxP3 co-expression $(F)$. The graphs display the percentages (the mean percentage values $\pm S D$ ) of $\mathrm{CD}^{+}{ }^{+} \mathrm{CD} 127_{\text {low }} \mathrm{CD} 25^{+} \mathrm{FoxP}^{+}$Tregs and $\mathrm{CD} 8^{+} \mathrm{CD} 25^{+} \mathrm{FoxP}^{+}{ }^{+}$Tregs for all donors $(n=10)$. * $p<0.05$ (ANOVA or Kruskal-Wallis).

CTLA-4 expression was significantly increased after incubation compared to freshly isolated T cells. For PD-1 marker, only percentage of $\mathrm{CD} 4^{+} \mathrm{PD}-1^{+} \mathrm{T}$ cells was significantly higher. In the case of FoxP3, we found different results. The percentage of $\mathrm{CD}^{+}{ }^{+} \mathrm{FoxP}^{+} \mathrm{T}$ cells was lower, but it was statistically significant only after overnight incubation in PBS containing $0.5 \%$ BSA. Furthermore, overnight incubation significantly increased the percentage of $\mathrm{CD}^{+} \mathrm{FoxP}^{+} \mathrm{T}$ cells when cells were stored in RPMI 1640 containing 10\% FBS compared to freshly isolated cells and cells stored in PBS alone (Table I).

No significant differences were found in the expression levels (measured as MFI) of individual markers, apart from the significantly decreased PD- $1 \mathrm{MFI}$ in $\mathrm{CD}^{+} \mathrm{T}$ cells, the significantly increased GITR MFI in $\mathrm{CD}^{+} \mathrm{T}$ cells, and FoxP3 MFI, which significantly decreased in both $\mathrm{CD} 4^{+}$and $\mathrm{CD} 8^{+}$ $\mathrm{T}$ cells compared to freshly isolated $\mathrm{T}$ cells (data not shown).

Finally, we investigated how overnight storage in different media affects the percentage of $\mathrm{T}$ cells with regulatory properties (Tregs), such as $\mathrm{CD}^{+}$Tregs (identified as $\mathrm{CD} 4^{+} \mathrm{CD} 127^{\text {low } /-} \mathrm{CD} 25^{+} \mathrm{FoxP}^{+}$) and $\mathrm{CD} 8^{+}$Tregs (identified as $\mathrm{CD}^{+} \mathrm{CD} 25^{+} \mathrm{FoxP}^{+}$) (Figure 3 ). We observed that the percentage of $\mathrm{CD} 4{ }^{+} \mathrm{CD} 127^{\text {low/-}} \mathrm{CD} 25^{+} \mathrm{FoxP} 3^{+}$Tregs increased after overnight incubation in all media with statistical significance in PBS and RPMI compared to freshly isolated $\mathrm{CD}^{+}$Tregs (Figure 3G). In contrast, the percentage of $\mathrm{CD} 8{ }^{+} \mathrm{CD} 25^{+} \mathrm{FoxP}^{+}$Tregs decreased in all incubation conditions compared to freshly isolated cells. Significant decrease was noted in PBS containing 0.5\% BSA and RPMI 1640 containing $10 \%$ FBS (Figure 3D).

\section{Discussion}

Storing PBMCs has always some negative effects, however, in certain situations it is unavoidable. The most common storage method of cells is freezing, but freezing could have significant effects on PBMC recovery, functionality and viability $(6,16)$. Peripheral blood is a source of proteins and other nutrients, ensuring adequate physical and chemical conditions for immune cells. Isolated PBMCs are free of natural factors necessary for survival, therefore, in vitro storage could be a challenge. All environmental conditions such as appropriate temperature, storage time, $\mathrm{pH}$ or 
composition of the medium can reduce not only the number of cells but they may also affect expression of individual markers on the examined population, which may affect the functions of these cells and finally the research results $(6$, $13,15,17)$. Incubation of PBMCs at $4^{\circ} \mathrm{C}$ overnight in a suitable medium could solve these problems. Therefore, in this study we evaluated the viability of PBMCs stored overnight at $4^{\circ} \mathrm{C}$ in four different media and also, the individual expression of $\mathrm{T}$ cell markers, such as CD25, CTLA-4, GITR, and PD-1, as well as the transcription factors FoxP3 and Helios, which are related to the regulatory function of $\mathrm{T}$ cells. In addition, due to the Treg relevance in autoimmune diseases, immune tolerance and allergy, we also studied the frequencies of not only $\mathrm{CD} 4^{+}$, but also of $\mathrm{CD} 8^{+}$ Tregs $\left(\mathrm{CD}^{+}\right.$Tregs defined as $\mathrm{CD} 4{ }^{+} \mathrm{CD} 127^{\mathrm{low} /-}$ $\mathrm{CD}_{25}{ }^{+} \mathrm{FoxP}^{+}{ }^{+}$and $\mathrm{CD}^{+}$Tregs as $\mathrm{CD} 8^{+} \mathrm{CD} 25^{+} \mathrm{FoxP}^{+}$).

Before analysis of the expression of $\mathrm{T}$ regulatory markers, we evaluated the viability of PBMCs. Freshly isolated PBMCs were incubated for $24 \mathrm{~h}$ at $4^{\circ} \mathrm{C}$ in four different media: PBS pH 7.3, PBS pH 7.3 containing 0.5\% BSA, RPMI 1640, and RPMI 1640 containing 10\% FBS. Firstly, using Muse Cell Analyzer, the highest PBMC viability was observed in RPMI 1640 containing $10 \%$ FBS. FBS is not only a source of biologically active proteins such as hormones and growth factors, but also a great source of microparticles, exosomes, and other factors. These substances could not only increase the viability of cells, but could also affect the production of cytokines by PBMCs, which can affect the activation of cells (18). Analysis of cell viability by flow cytometry showed that for both lymphocytes and the whole leukocyte population, the best medium for PBMC overnight storage at $4^{\circ} \mathrm{C}$ was RPMI 1640 without FBS supplementation. These different results may indicate that the choice of the appropriate method to assess cell viability is important. Furthermore, it is important to define the cell population of study, as well as the next experimental steps. Determining cell viability using Muse Cell Analyzer as a method, suffers from the fact that it cannot properly separate living cells from cell debris, which could have affected the obtained results. Flow cytometry is an accurate method, which can determine the viability of a particular cell population.

Detailed immunophenotyping of $\mathrm{T}$ cells by flow cytometry showed that after overnight incubation at $4^{\circ} \mathrm{C}$ some of $\mathrm{T}$ cell markers were influenced. Significant changes were found mainly for CD25, CTLA-4, PD-1 and FoxP3 expression, both on $\mathrm{CD}^{+}$and $\mathrm{CD}^{+} \mathrm{T}$ cells. These could suggest that these markers are sensitive to incubation at $4{ }^{\circ} \mathrm{C}$, and these changes should be considered in the final results.

Furthermore, we observed that the overnight incubation at $4^{\circ} \mathrm{C}$ in four different media conversely affected the percentage of $\mathrm{CD}^{+}$and $\mathrm{CD} 8+$ Tregs. Consistent with these observations, experimental determination of appropriate storage conditions for isolated cells should be standard laboratory practice.
Substances released into the environment by dying cells during storage at $4^{\circ} \mathrm{C}$ can activate and alter the phenotype of $\mathrm{T}$ cells. Therefore, when analysing experimental results, one should remember the differences resulting from storage conditions. Further, it is important to determine whether and to what extent PBMC storage at $4^{\circ} \mathrm{C}$ affects Tregs functionality according to the expression of CD25, CTLA-4, PD-1 and FoxP3 markers.

\section{Conflicts of Interest}

The Authors declare no conflict of interest in relation to this study.

\section{Authors' Contributions}

All Authors contributed to the review conception and design. MG performed the experiments, analysed data and wrote the manuscript. MM analysed data and wrote the manuscript. KDL analysed the data and corrected the manuscript.

\section{Acknowledgements}

This work was supported by grants from the TEAM TECH/2017$4 / 22$ project carried out within the TEAM TECH programme of the Foundation for Polish Science co-financed by the European Union under the European Regional Development Fund.

\section{References}

1 Kizhakeyil A, Ong ST, Fazil MHUT, Chalasani MLS, Prasannan $\mathrm{P}$ and Verma NK: Isolation of human peripheral blood Tlymphocytes. In: T-Cell Motility. N.K. Verma (eds.). New York, NY, USA, Humana Press, pp. 11-17, 2019. PMID: 30610593. DOI: 10.1007/978-1-4939-9036-8_2

2 Kleiveland CR: Peripheral blood mononuclear cells. In: The impact of food bioactives on health: in vitro and ex vivo models. K. Verhoeckx, P. Cotter, I. López-Expósito, C. Kleiveland, T. Lea, A. Mackie, T. Requena, D. Swiatecka, H. Wichers (eds.). Cham, Switzerland, Springer, pp. 161-167, 2015. PMID: 29787062. DOI: $10.1007 / 978-3-319-16104-4 \_15$

3 Riedhammer C, Halbritter D and Weissert R: Peripheral blood mononuclear cells: Isolation, freezing, thawing, and culture. In: Multiple Sclerosis. R. Weissert (eds.). New York, NY, USA, Humana Press, pp. 53-61, 2015. PMID: 25092056. DOI: 10.1007/7651_2014_99

4 Askenasy N, Kaminitz A and Yarkoni S: Mechanisms of T regulatory cell function. Autoimmun Rev 7(5): 370-375, 2008. PMID: 18486924. DOI: 10.1016/j.autrev.2008.03.001

5 Buszko $M$ and Shevach EM: Control of regulatory $\mathrm{T}$ cell homeostasis. Curr Opin Immunol 67: 18-26, 2020. PMID: 32810642. DOI: 10.1016/j.coi.2020.07.001

6 Daniele N, Scerpa MC, Landi F, Caniglia M, Miele MJ, Locatelli F, Isacchi $\mathrm{G}$ and Zinno F: Treg cells: Collection, processing, storage and clinical use. Pathol Res Pract 207(4): 209-215, 2011. PMID: 21397410. DOI: 10.1016/j.prp.2011.02.003

7 Sakaguchi S, Mikami N, Wing JB, Tanaka A, Ichiyama K and Ohkura N: Regulatory T Cells and Human Disease. Annu Rev Immunol 38: 541-566, 2020. PMID: 32017635. DOI: 10.1146/ annurev-immunol-042718-041717 
8 Savage PA, Klawon DEJ and Miller CH: Regulatory T cell development. Annu Rev Immunol 38: 421-453, 2020. PMID: 31990619. DOI: 10.1146/annurev-immunol-100219-020937

9 Sun L, Jin H and Li H: GARP: a surface molecule of regulatory $\mathrm{T}$ cells that is involved in the regulatory function and TGF- $\beta$ releasing. Oncotarget 7(27): 42826-42836, 2016. PMID: 27095576. DOI: $10.18632 /$ oncotarget. 8753

10 Zhang $\mathrm{X}$, Olsen $\mathrm{N}$ and Zheng SG: The progress and prospect of regulatory $\mathrm{T}$ cells in autoimmune diseases. J Autoimmun 111: 102461, 2020. PMID: 32305296. DOI: 10.1016/j.jaut.2020.102461

11 Dinesh RK, Skaggs BJ, la Cava A, Hahn BH and Singh RP: $\mathrm{CD}^{+}$Tregs in lupus, autoimmunity, and beyond. Autoimmun Rev 9(8): 560-568, 2010. PMID: 20385256. DOI: 10.1016/ j.autrev.2010.03.006

12 Smith TRF and Kumar V: Revival of CD8+ Treg-mediated suppression. Trends Immunol 29(7): 337-342, 2008. PMID: 18514574. DOI: $10.1016 /$ j.it.2008.04.002

13 Bergman M, Bessler H, Salman H and Djaldetti M: Relationship between temperature and apoptosis of human peripheral blood mononuclear cells. Int J Hematol 77(4): 351-353, 2003. PMID: 12774922. DOI: $10.1007 / \mathrm{BF} 02982642$

14 Dagur PK and McCoy JP: Collection, storage, and preparation of human blood cells. Curr Protoc Cytom 73(1): 5.1.1-5.1.16, 2015. PMID: 26132177. DOI: 10.1002/0471142956.cy0501s73

15 Higdon LE, Lee K, Tang Q and Maltzman JS: Virtual global transplant laboratory standard operating procedures for blood collection, PBMC isolation, and storage. Transplantation Direct 2(9): e101, 2016. PMID: 27795993. DOI: 10.1097/txd.0000 000000000613
16 Yang J, Diaz N, Adelsberge J, Zhou X, Stevens R, Rupert A, Metcalf JA, Baseler M, Barbon C, Imamichi, T, Lempicki R and Cosentino LM: The effects of storage temperature on PBMC gene expression. BMC Immunol 17: 2016. PMID: 26979060. DOI: $10.1186 / \mathrm{s} 12865-016-0144-1$

17 Gołab K, Grose R, Placencia V, Wickrema A, Solomina J, Tibudan M, Konsur E, Ciepły K, Marek-Trzonkowska N, Trzonkowski P, Millis JM, Fung J and Witkowski P: Cell banking for regulatory $\mathrm{T}$ cell-based therapy: Strategies to overcome the impact of cryopreservation on the Treg viability and phenotype. Oncotarget 9(11): 9728-9740, 2018. PMID: 29515766. DOI: 10.18632/oncotarget.23887

18 van der Valk J, Mellor D, Brands R, Fischer R, Gruber F, Gstraunthaler G, Hellebrekers L, Hyllner J, Jonker FH, Prieto P, Thalen $\mathrm{M}$ and Baumans V: The humane collection of fetal bovine serum and possibilities for serum-free cell and tissue culture. Toxicol In Vitro 1(18): 1-12, 2004. PMID: 14630056. DOI: $10.1016 /$ j.tiv.2003.08.009
Received October 21, 2020

Revised November 10, 2020

Accepted November 17, 2020 